\title{
Erratum to: The limit to exercise tolerance in humans: mind over muscle?
}

\author{
Samuele Maria Marcora $\cdot$ Walter Staiano
}

Published online: 15 September 2010

(C) Springer-Verlag 2010

\section{Erratum to: Eur J Appl Physiol (2010) 109:763-770 DOI 10.1007/s00421-010-1418-6}

The recent publication by Samuele Maria Marcora and Walter Staiano entitled "The limit to exercise tolerance in humans: mind over muscle?" (Eur J Appl Physiol 109(4):763-770, 2010; published online on March 11, 2010; published in print in July 2010) has provoked considerable discussion. This includes a Letter to the Editor by Mark Burnley entitled "The limit to exercise tolerance in humans: validity compromised by failing to account for the power-velocity relationship" (Eur J Appl Physiol 109(6):1225-1226, 2010; published online on April 7, 2010; published in print in August 2010). We regret to note, however, that due to an oversight in the publication process, the Authors' response to this Letter was actually published prior to Dr Burnley's Letter. This Response can be found in Eur J Appl Physiol 109(4):787-788, 2010; published online on May 5, 2010; published in print in July 2010). We apologise to both Dr Marcora and Dr Staiano and also to Dr Burnley for any confusion that has resulted.

The online version of the original article can be found under doi: 10.1007/s00421-010-1418-6.

S. M. Marcora $(\bowtie) \cdot$ W. Staiano

School of Sport, Health and Exercise Sciences,

Bangor University, Normal Site, Holyhead Road,

Bangor, Gwynedd LL57 2PZ, Wales, UK

e-mail: s.m.marcora@bangor.ac.uk 